\title{
Efeitos das Faixas de Controle do CaPim-BraguiáRIa (Brachiaria decumbens) no Desenvolvimento Inicial e na PRodutividade do CAFEeIro (Coffea arabica) ${ }^{1}$
}

\author{
Effect of Brachiaria decumbens Control Bands on the Initial Development and Productivity of \\ Coffea arabica
}

\begin{abstract}
SOUZA, L.S. ${ }^{2}$, LOSASSO, P.H.L. ${ }^{4}$, OSHIIWA, M. ${ }^{3}$, GARCIA, R.R. ${ }^{4}$ e GOES FILHO, L.A. ${ }^{5}$
RESUMO - Neste trabalho, objetivou-se avaliar os efeitos das diferentes faixas de controle do capim-braquiária (Brachiaria decumbens) no desenvolvimento inicial e na produtividade do cafeeiro (Coffea arabica). O experimento foi conduzido entre março de 2002 e maio de 2004, na Fazenda Cachoeiras de São Pedro, município de Garça-SP. As plantas de café utilizadas foram Mundo Novo (var. 388/17) no espaçamento de $1,40 \mathrm{~m}$ na linha de plantio e 4,0 $\mathrm{m}$ nas entrelinhas, sendo duas mudas por cova. Os tratamentos foram constituídos pelas seguintes faixas de controle: $0,25,50,75,100,125$ e $150 \mathrm{~cm}$ de largura para cada lado da linha cultivada do cafeeiro. O delineamento experimental utilizado foi de blocos casualizados, com quatro repetições. Foram avaliados a altura e o diâmetro na base do caule das mudas de café, a produção bruta e a produção beneficiada dos grãos. Pelos resultados obtidos, pode-se concluir que a largura mínima da faixa de controle a ser utilizada foi de $100 \mathrm{~cm}$ de cada lado da linha, a fim de manter as plantas de café livres da interferência de capim-braquiária.
\end{abstract}

Palavras-chave: manejo de plantas daninhas, braquiária, café, competição.

\begin{abstract}
This work aimed to evaluate the effect of Brachiaria decumbens control bands on the initial development and productivity of Coffea arabica. The experiment was conducted from March 2002 to May 2004 in Cachoeiras de São Pedro Farm in Garça-SP. The coffee plants used were Mundo Novo var. 388/17. The treatments were constituted by the respective control bands: $0,25,50,75,100,125$ and $150 \mathrm{~cm}$ width for each side of the cultivated line and were arranged in a randomized complete block design with four replications. The following characteristics were evaluated: height and stem base diameter of the coffee seedlings, gross production and industrialized grain production. Based on the results obtained, the minimum control band width to be used should be equal to or higher than $100 \mathrm{~cm}$ on each side of the plantation line in order to maintain the young coffee plants free from $\boldsymbol{B}$. decumbens interference.
\end{abstract}

Key words: weed management Brachiaria decumbens, coffee, competion.

\section{INTRODUÇÃO}

As lavouras de café em formação são muito suscetíveis à interferência das plantas daninhas na linha de plantio, principalmente da espécie $B$. decumbens, que pode reduzir o desenvolvimento e comprometer a produtividade dos cafeeiros. Atualmente, a recomendação é manter a linha de plantio livre de plantas daninhas, sendo para isso utilizada pelos

Recebido para publicação em 7.3.2006 e na forma revisada em 10.11.2006.

Parte da dissertação do segundo autor apresentada à FCA-UNIMAR para obtenção do título de Mestre em Agronomia. 2 Prof. Dr. do Departamento de Fitotecnia, Faculdade de Ciências Agrárias, Universidade de Marília - FCA/UNIMAR; ${ }^{3}$ Prof ${ }^{a}$. Dra ${ }^{a}$. do Departamento de Bioestatística - UNIMAR. ${ }^{4}$ Eng.-Agrônomo Consultor <pedrolosasso@ yahoo.com.br>; ${ }^{5}$ Acadêmico do Curso de Engenharia Agronômica - FCA/UNIMAR, Av. Hygino Muzzi Filho, 1001, 17525-010 Marília-SP, <lsouzaca@unimar.br>. 
produtores uma faixa de controle de 50 a $80 \mathrm{~cm}$ de cada lado da linha de plantio das mudas de café (Silva \& Ronchi, 2004).

As faixas de controle podem ser definidas como a distância livre da incidência de plantas daninhas para a linha em que estão presentes as plantas cultivadas (Toledo et al., 2000). A metodologia de faixas de controle é usada mais freqüentemente em culturas perenes, principalmente na fase de formação. Entretanto, Merotto Jr. et al. (2001) estudaram o efeito do controle de plantas daninhas em faixas na linha ou na entrelinha e avaliaram suas conseqüências sobre a competição interespecífica na cultura do milho.

Toledo et al. (2000) demonstraram que a faixa de controle de capim-braquiária no desenvolvimento inicial em plantas de eucalipto deveria ser igual ou superior a $100 \mathrm{~cm}$, pois mostraram-se superiores em diâmetro, altura e velocidade de crescimento absoluto nessa faixa. A largura da faixa de de $50 \mathrm{~cm}$ "no limpo" que era utilizada naquela época, pela maior parte das empresas florestais, era insuficiente para manter as plantas cultivadas livres da interferência negativa das plantas de B. decumbens.

Dias et al. (2004) avaliaram a influência das faixas de controle de 0, 40, 80, 120, 160, 200 e $250 \mathrm{~cm}$, posicionadas na linha e na entrelinha do café. A população de plantas daninhas era diversificada, com predominância de apaga-fogo (Alternanthera tenella), capimamargoso (Digitaria insularis) e trapoeraba (Commelina benghalensis). No primeiro ano agrícola não houve diferença significativa na altura e no diâmetro de caule das plantas de café, mas no terceiro ano a largura mínima da faixa de controle das plantas daninhas necessária para um bom desenvolvimento da cultura do café - foi de $60 \mathrm{~cm}$ de cada lado da linha cultivada.

Observa-se variação da largura das faixas de controle em relação à espécie da comunidade infestante presente na área experimental. Desse modo, esta pesquisa teve como objetivo estudar os efeitos da variação na largura das faixas de controle do capimbraquiária (B. decumbens) sobre o desenvolvimento inicial de mudas e a produtividade do cafeeiro.

\section{MATERIAL E MÉTODOS}

O experimento foi instalado e conduzido na Fazenda Cachoeiras de São Pedro, distrito de Jafa, município de Garça-SP, localizado na latitude $22^{\circ} 10^{\prime} 29,78^{\prime \prime} \mathrm{S}$ e na longitude $49^{\circ} 43^{\prime}$ 22,05" W. O solo da área experimental é classificado como Argissolo Vermelho-Amarelo, transição abrupta. Segundo a classificação climática de Koeppen, o clima predominante na região é do tipo Cwa. É caracterizado pelo clima tropical com 654,64 m de altitude, com inverno seco e verão úmido (Lombardi Neto \& Drugowich, 1994).

Inicialmente foi feita uma calagem em área total necessária para elevar a saturação por base em $70 \%$ e posteriormente realizado o preparo convencional do solo com uma gradagem aradora e uma gradagem niveladora. A adubação de plantio foi constituída por $2 \mathrm{~kg}$ de esterco de galinha e $200 \mathrm{~g}$ de termofosfato com micronutrientes por cova. Foi utilizada a variedade de café Mundo Novo enxertada em Robusta (var.388/17), transplantadas em 20 de março de 2002, com espaçamento de 1,40 m na linha de plantio e 4,0 m nas entrelinhas, sendo duas mudas por cova. As parcelas experimentais foram constituídas de duas linhas de plantio por $10 \mathrm{~m}$ de comprimento, totalizando $40 \mathrm{~m}^{2}$. Como área útil, consideraramse as duas linhas externas, e as extremidades destas linhas com 1 metro a menos de cada, como bordaduras, totalizando $32 \mathrm{~m}^{2}$.

Os tratos culturais, exceto o controle das plantas daninhas nos dois primeiros anos, foram realizados de acordo com a rotina da fazenda. A colheita foi feita manualmente em 12 de maio de 2004.

Os tratamentos experimentais foram constituídos de faixas de controle durante os 25 meses iniciais, a saber: 0, 25, 50, 75, 100, 125 e $150 \mathrm{~cm}$ de cada lado da linha de transplante. O delineamento experimental foi de blocos casualizados, com quatro repetições.

Foram avaliadas as plantas úteis de café quanto à altura e ao diâmetro da base do caule, aos 65, 146, 196, 235, 305, 370, 411, 502, 586 e 614 dias após o transplante (DAT) das mudas, constituindo 10 épocas de avaliação. O diâmetro do caule é um dos melhores indicadores da competição de plantas daninhas com 
a cultura do café até três anos de idade (Friessleben et al., 1991). As avaliações foram mais freqüentes, com menor espaço de tempo, nos períodos chuvosos. No final do experimento, as plantas foram avaliadas quanto à produtividade em grãos.

Foi colhida a totalidade dos grãos de café presentes nas plantas da área útil de cada parcela. A pesagem foi realizada no mesmo dia, para se obter a produção de café verde, cereja e seco por parcela, e foi medida a densidade dos grãos, para determinação de massa úmida $\left(0,61 \mathrm{~kg} \mathrm{dm}^{-3}\right)$. Logo em seguida, os grãos foram secos em estufa a $60{ }^{\circ} \mathrm{C}$ até peso constante, para determinação da massa seca. Posteriormente, os grãos foram descascados, para se obter a produção beneficiada. Para estimar a produtividade beneficiada $\left(\mathrm{kg} \mathrm{ha}^{-1}\right)$, foi utilizado peso dos grãos de café a $0 \%$ de umidade. É importante ressaltar que, para os grãos de café preservarem suas características de odor, sabor e aspecto, devem ser comercializados em umidade de $11 \%$.

Os resultados obtidos na presente pesquisa foram submetidos à análise de variância; quando se observou diferença significativa entre os tratamentos, os dados foram submetidos ao teste de Bonferroni e as médias comparadas duas a duas. Na produção de grãos de café, procedeu-se à comparação dos tratamentos por contrastes de médias. Em vez de comparar os valores de $\mathrm{F}$ obtidos com os valores tabelados em níveis de 1,5 e $10 \%$ de probabilidade, optou-se pelo nível de significância, que corresponde à probabilidade de erro quando se admite que as duas médias comparadas são diferentes (Souza et al., 2003).

\section{RESULTADOS E DISCUSSÃO}

A densidade média do capim-braquiária observada durante o período experimental foi de 14 plantas $\mathrm{m}^{-2}$ na área total das parcelas, dividida em 6,5 na linha e 7,5 plantas $\mathrm{m}^{-2}$ na entrelinha de transplante das mudas de café, com a biomassa seca acumulada na área total da parcela testemunha de $1.022,50 \mathrm{~g} \mathrm{~m}^{-2}$. Segundo Ronchi (2002), a presença de capimbraquiária, crescendo juntamente com a planta de café, reduz o número de folhas, a altura, o diâmetro do caule e, principalmente, a biomassa seca da parte aérea das plantas de café.
As reduções médias foram de $42 \%$ na biomassa seca da parte aérea de plantas de café devido à interferência de cinco plantas por vaso de B. decumbens, o que justifica o controle do capim-braquiária na presente pesquisa.

Nas Tabelas 1 e 2 estão os resultados referentes ao efeito das faixas de controle sobre a altura e o diâmetro do caule das mudas de café, respectivamente. Na primeira avaliação, realizada aos 65 dias após o transplante das mudas (DAT), não foi observada diferença significativa quanto à altura e ao diâmetro do caule. Esse resultado já era esperado, pois as mudas apresentaram homogeneidade inicial em altura e diâmetro do caule. As diferenças significativas foram observadas a partir da segunda (146 DAT) até a última avaliação (614 DAT). Observou-se que, quanto maior o tempo em relação ao transplante, maior foi o efeito das faixas de controle na altura e no diâmetro dos cafeeiros. Os coeficientes de variação apresentaram-se baixos, confirmando o crescimento homogêneo dentro de cada parcela (Tabela 1).

Com relação à altura das mudas de café, foi verificado, aos 146 DAT, que faixas de controle de 100, 125 e $150 \mathrm{~cm}$ promoveram maior desenvolvimento em altura, quando comparadas com a testemunha não-capinada e com as faixas de 25, 50 e $75 \mathrm{~cm}$. De acordo com Blanco et al. (1982), a competição, principalmente por luz e nutrientes, é grande em lavouras em formação, pois as plantas de café ainda jovens deixam grande área de solo livre, favorecendo, dessa forma, a infestação e o crescimento das espécies infestantes. Outro fator de competição entre planta daninha e cultura do café são as raízes absorventes do cafeeiro que crescem superficialmente no solo, onde a maioria das raízes das plantas daninhas ocorre (Njoroge, 1994).

A partir dos 305 DAT, os efeitos das diferentes faixas de controle sobre o capimbraquiária começaram a sobressair, ou seja, as plantas de café dos tratamentos de 100, 125 e $150 \mathrm{~cm}$ mostraram-se com maior altura. Observou-se que até o último dia de avaliação (614 DAT) os tratamentos com 125 e $150 \mathrm{~cm}$ somente diferiram estatisticamente entre si quanto à diferença de altura aos 196 e aos 502 DAT (Tabela 1). 
Tabela 1 - Valores médios da altura da parte aérea das mudas de café submetidas ao efeito de faixas de controle em várias épocas de avaliação. Marília-SP, 2005

\begin{tabular}{|c|c|c|c|c|c|c|c|c|c|c|}
\hline \multirow{2}{*}{$\begin{array}{c}\text { Faixa de } \\
\text { controle } \\
(\mathrm{cm})\end{array}$} & \multicolumn{9}{|c|}{ Época de avaliação (DAT) } \\
\cline { 2 - 11 } & 65 & 146 & 196 & 235 & 305 & 370 & 411 & 502 & 586 & 614 \\
\hline $\mathrm{T} 1-0$ & 22,87 & $24,41 \mathrm{a}$ & $24,77 \mathrm{a}$ & $25,80 \mathrm{a}$ & $28,29 \mathrm{a}$ & $29,20 \mathrm{a}$ & $27,16 \mathrm{a}$ & $27,64 \mathrm{a}$ & $26,28 \mathrm{a}$ & $7,56 \mathrm{a}$ \\
\hline $\mathrm{T} 2-25$ & 25,63 & $27,90 \mathrm{ab}$ & $28,09 \mathrm{ab}$ & $30,13 \mathrm{ab}$ & $33,54 \mathrm{~b}$ & $33,92 \mathrm{a}$ & $35,93 \mathrm{~b}$ & $27,10 \mathrm{a}$ & $27,64 \mathrm{a}$ & $28,31 \mathrm{~b}$ \\
\hline $\mathrm{T} 3-50$ & 23,17 & $26,98 \mathrm{ab}$ & $28,19 \mathrm{ab}$ & $30,49 \mathrm{~b}$ & $32.96 \mathrm{ab}$ & $35,32 \mathrm{ab}$ & $34,77 \mathrm{~b}$ & $32,08 \mathrm{a}$ & $32,13 \mathrm{a}$ & $42,62 \mathrm{c}$ \\
\hline $\mathrm{T} 4-75$ & 25,18 & $30,25 \mathrm{bc}$ & $30,77 \mathrm{bc}$ & $34,09 \mathrm{bc}$ & $37,11 \mathrm{~b}$ & $41,41 \mathrm{~b}$ & $42,39 \mathrm{c}$ & $42,08 \mathrm{~b}$ & $42,05 \mathrm{~b}$ & $48,59 \mathrm{c}$ \\
\hline $\mathrm{T} 5-100$ & 25,40 & $30,93 \mathrm{bc}$ & $33,17 \mathrm{c}$ & $37,43 \mathrm{~cd}$ & $42,29 \mathrm{c}$ & $49,04 \mathrm{c}$ & $51,25 \mathrm{~cd}$ & $55,44 \mathrm{c}$ & $57,53 \mathrm{c}$ & $64,32 \mathrm{~d}$ \\
\hline $\mathrm{T} 6-125$ & 24,66 & $31,62 \mathrm{c}$ & $35,09 \mathrm{c}$ & $39,92 \mathrm{~d}$ & $45,65 \mathrm{~cd}$ & $50,93 \mathrm{~cd}$ & $53,65 \mathrm{de}$ & $59,85 \mathrm{c}$ & $69,13 \mathrm{de}$ & $79,00 \mathrm{ef}$ \\
\hline $\mathrm{T} 7-150$ & 25,48 & $32,78 \mathrm{c}$ & $41,63 \mathrm{~d}$ & $43,520 \mathrm{~d}$ & $50,39 \mathrm{~d}$ & $56,57 \mathrm{~d}$ & $59,41 \mathrm{e}$ & $67,85 \mathrm{~d}$ & $74,10 \mathrm{e}$ & $87,50 \mathrm{f}$ \\
\hline $\mathrm{F}$ & 0,91 & 4,06 & 9,13 & 10,63 & 14,66 & 142,99 & 167,25 & 335,32 & 330,96 & 285,83 \\
\hline $\mathrm{CV}(\%)$ & 9,6 & 13,0 & 19,5 & 19,5 & 21,3 & 25,1 & 27,8 & 36,8 & 42,0 & 55,0 \\
\hline
\end{tabular}

Médias seguidas pelas mesmas letras minúsculas não diferem estatisticamente entre si, nas colunas, pelo teste de Bonferroni a $5 \%$ de probabilidade.

Tabela 2 - Valores médios do diâmetro do caule das mudas de café submetidas ao efeito de faixas de controle em várias épocas de avaliação. Marília-SP, 2005

\begin{tabular}{|c|c|c|c|c|c|c|c|c|c|c|}
\hline \multirow{2}{*}{$\begin{array}{c}\text { Faixa de } \\
\text { controle } \\
(\mathrm{cm})\end{array}$} & \multicolumn{10}{|c|}{ Época de avaliação (DAT) } \\
\cline { 2 - 11 } & 65 & 146 & 196 & 235 & 305 & 370 & 411 & 502 & 586 & 614 \\
\hline $\mathrm{T} 1-0$ & 0,39 & $0,4 \mathrm{a}$ & $0,38 \mathrm{a}$ & $0,38 \mathrm{a}$ & $0,43 \mathrm{a}$ & $0,38 \mathrm{a}$ & $0,41 \mathrm{a}$ & $0,45 \mathrm{a}$ & $0,39 \mathrm{a}$ & $0,12 \mathrm{a}$ \\
\hline $\mathrm{T} 2-25$ & 0,42 & $0,41 \mathrm{a}$ & $0,41 \mathrm{a}$ & $0,45 \mathrm{ab}$ & $0,47 \mathrm{a}$ & $0,53 \mathrm{ab}$ & $0,55 \mathrm{a}$ & $0,51 \mathrm{a}$ & $0,39 \mathrm{a}$ & $0,45 \mathrm{~b}$ \\
\hline $\mathrm{T} 3-50$ & 0,42 & $0,45 \mathrm{ab}$ & $0,43 \mathrm{a}$ & $0,50 \mathrm{bc}$ & $0,57 \mathrm{a}$ & $0,58 \mathrm{bc}$ & $0,59 \mathrm{ab}$ & $0,67 \mathrm{ab}$ & $0,54 \mathrm{ab}$ & $0,66 \mathrm{bc}$ \\
\hline $\mathrm{T} 4-75$ & 0,42 & $0,50 \mathrm{bc}$ & $0,49 \mathrm{~b}$ & $0,59 \mathrm{c}$ & $0,71 \mathrm{~b}$ & $0,71 \mathrm{c}$ & $0,77 \mathrm{~b}$ & $0,86 \mathrm{~b}$ & $0,81 \mathrm{~b}$ & $0,82 \mathrm{c}$ \\
\hline $\mathrm{T} 5-100$ & 0,45 & $0,55 \mathrm{~cd}$ & $0,59 \mathrm{c}$ & $0,70 \mathrm{~d}$ & $0,93 \mathrm{c}$ & $1,06 \mathrm{de}$ & $1,24 \mathrm{c}$ & $1,31 \mathrm{c}$ & $1,37 \mathrm{c}$ & $1,34 \mathrm{~d}$ \\
\hline $\mathrm{T} 6-125$ & 0,45 & $0,60 \mathrm{~d}$ & $0,65 \mathrm{~cd}$ & $0,81 \mathrm{ef}$ & $1,10 \mathrm{~d}$ & $1,21 \mathrm{ef}$ & $1,37 \mathrm{c}$ & $1,46 \mathrm{c}$ & $1,63 \mathrm{c}$ & $1,69 \mathrm{e}$ \\
\hline $\mathrm{T} 7-150$ & 0,45 & $0,60 \mathrm{~d}$ & $0,69 \mathrm{~d}$ & $0,90 \mathrm{f}$ & $1,29 \mathrm{e}$ & $1,38 \mathrm{f}$ & $1,60 \mathrm{~d}$ & $1,73 \mathrm{~d}$ & $1,92 \mathrm{~d}$ & $2,06 \mathrm{f}$ \\
\hline $\mathrm{F}$ & 23,17 & 74,92 & 204,81 & 194,13 & 351,4 & 264,14 & 339,73 & 304,1 & 286,0 & 363,37 \\
\hline $\mathrm{CV}(\%)$ & 8,4 & 19,4 & 24,5 & 31,6 & 41,2 & 45,5 & 49,2 & 49,9 & 62,0 & 67,4 \\
\hline
\end{tabular}

Médias seguidas pelas mesmas letras minúsculas não diferem estatisticamente entre si, nas colunas, pelo teste de Bonferroni a 5\% de probabilidade.

Aos 370 DAT, a testemunha e as faixas de controle com 25 e $50 \mathrm{~cm}$ de largura provocaram redução e permaneceram constantes até 586 DAT. A partir dessa época, nas faixas com $50 \mathrm{~cm}$ de largura os cafeeiros retomaram o crescimento. Nas faixas com $25 \mathrm{~cm}$, a altura das mudas permaneceu com média de $27,68 \mathrm{~cm}$. A testemunha apresentou decréscimo acentuado no crescimento até a última época de avaliação (614 DAT), o que se deveu à morte das mudas de café ( Tabela 1).

Quanto ao desenvolvimento do diâmetro do caule (Tabela 2), os resultados tiveram comportamento semelhante ao da altura. As diferenças significativas a 5\% pelo teste de Bonferroni mostraram que, quanto maior a largura da faixa de controle, maior o diâmetro do caule das plantas de café. A partir de 196 DAT, cafeeiros com faixas de controle de $150 \mathrm{~cm}$ apresentam maior diâmetro de caule em valores absolutos; contudo, aos 305 DAT e a partir de 411 DAT esse valor foi estatisticamente superior aos valores de diâmetro dos outros tratamentos.

Esses resultados corroboram o trabalho de pesquisa de Toledo et al. (2000). Esses autores 
verificaram que aos 390 DAT as plantas de eucalipto que cresceram nas parcelas com faixas de controle constantes ou crescentes, iguais ou superiores a $100 \mathrm{~cm}$, foram superiores em diâmetro, altura e velocidade de crescimento absoluto. Entretanto, Dias et al. (2004) avaliaram a influência da faixa de controle das plantas daninhas sobre o crescimento do cafeeiro e concluíram que a largura mínima de controle das plantas daninhas, para um bom desenvolvimento da cultura, foi de $60 \mathrm{~cm}$ de cada lado das mudas.

Nas avaliações referentes à produção do cafeeiro, apenas aqueles com faixa de controle de capim-braquiária igual ou superior a $100 \mathrm{~cm}$ produziram grãos no segundo ano agrícola após implantação do experimento (Tabela 3). As características de produção do cafeeiro apresentaram elevados coeficientes de variação. Esses valores justificam-se pela ausência de produção de grãos dos tratamentos de 1 a 4 . O efeito de tratamentos foi significativo em baixos níveis de probabilidade para todas as características analisadas, quando os tratamentos com produção (100, 125 e $150 \mathrm{~cm}$ ) foram comparados com a testemunha (sem produção).
Para a produção bruta (kg por parcela) e produtividade beneficiada $\left(\mathrm{kg} \mathrm{ha}^{-1}\right)$, os efeitos foram intensificados pelo aumento da largura de faixas; as maiores médias foram verificadas nas faixas de controle de 125 e $150 \mathrm{~cm}$.

Na Tabela 3, o coeficiente de secagem se refere à perda de água no processo de secagem, e o coeficiente de grãos descascados, à perda de água na secagem e de casca em porcentagem, que significam o peso líquido depois dos processos de secagem e benefício, respectivamente. Para o coeficiente de secagem e da casca de grãos, as faixas de 100 a $150 \mathrm{~cm}$ não provocaram níveis diferenciados nas médias desses coeficientes. No coeficiente de secagem, a faixa de $150 \mathrm{~cm}$ foi a que apresentou maior teor de partículas sólidas, ou seja, maior biomassa seca dos grãos com casca em relação às faixas de 100 e $125 \mathrm{~cm}$. Entretanto, na característica coeficiente de casca a faixa de $150 \mathrm{~cm}$, juntamente com a de $125 \mathrm{~cm}$, proporcionou alta porcentagem de casca no grão de café.

Analisando conjuntamente a fase de desenvolvimento e a de produção do experimento, verificou-se, primeiramente, que as plantas de café das parcelas com faixa de controle inferior

Tabela 3 - Valores médios de produção bruta, coeficiente de secagem do grão, coeficiente de grão descascado e produtividade beneficiada do cafeeiro, com os níveis de significância para os contrastes entre os tratamentos. Marília, 2005

\begin{tabular}{|c|c|c|c|c|}
\hline $\begin{array}{l}\text { Tratamento } \\
\qquad(\mathrm{cm})\end{array}$ & $\begin{array}{l}\text { Produção bruta } \\
(\mathrm{kg})\end{array}$ & $\begin{array}{l}\text { Coeficiente de } \\
\text { secagem do grão } \\
(\%)\end{array}$ & $\begin{array}{c}\text { Coeficiente de grão } \\
\text { descascado } \\
(\%)\end{array}$ & $\begin{array}{c}\text { Produtividade } \\
\text { beneficiada } \\
\left(\mathrm{kg} \mathrm{ha}^{-1}\right)\end{array}$ \\
\hline $\mathrm{T} 1-0$ & 0 & 0 & 0 & 0 \\
\hline $\mathrm{T} 2-25$ & 0 & 0 & 0 & 0 \\
\hline $\mathrm{T} 3-50$ & 0 & 0 & 0 & 0 \\
\hline $\mathrm{T} 4-75$ & 0 & 0 & 0 & 0 \\
\hline $\mathrm{T} 5-100$ & 0,64 & 44 & 53 & 34,84 \\
\hline $\mathrm{T} 6-125$ & 2,83 & 44 & 46 & 148,12 \\
\hline $\mathrm{T} 7-150$ & 4,21 & 49 & 45 & 234,12 \\
\hline Níveis de significância de F & $\alpha^{*}$ & $\alpha$ & $\alpha$ & $\alpha$ \\
\hline T1 vs T5 & 9,38 & 0,01 & 0,01 & 9,46 \\
\hline T1 vs T6 & 6,43 & 0,01 & 0,01 & 6,78 \\
\hline $\mathrm{T} 1$ vs $\mathrm{T} 7$ & 0,60 & 0,01 & 0,01 & 0,95 \\
\hline T5 vs T6 & 12,31 & 48,37 & 7,10 & 13,07 \\
\hline T5 vs T7 & 2,35 & 5,06 & 4,91 & 2,87 \\
\hline T6 vs T7 & 9,81 & 4,92 & 39,69 & 5,19 \\
\hline CV $(\%)$ & 177,0 & 118,2 & 118,5 & 180,6 \\
\hline
\end{tabular}

* Porcentagem 
a $100 \mathrm{~cm}$ apresentaram reduções mais intensas no crescimento em altura e no diâmetro do caule. Os melhores resultados na produção e na produtividade foram obtidos a partir de $125 \mathrm{~cm}$ de largura de faixa de controle.

Nas condições em que foi realizada a presente pesquisa, pode-se concluir que a largura mínima da faixa de controle a ser utilizada foi igual ou superior a $100 \mathrm{~cm}$ de cada lado da linha, a fim de manter as plantas de café livres da interferência de capim-braquiária.

\section{LITERATURA CITADA}

BLANCO, H. G.; OLIVEIRA, D. A.; PUPO, E. I. H. Período de competição de uma comunidade natural de mato em uma cultura de café em formação. Biológico, v. 48, n. 1, p. 9-20, 1982.

DIAS, T. C. S; ALVES, P. L. C. A.; LEMES, L. N. Efeito da faixa de controle das plantas daninhas sobre o crescimento do cafeeiro. Ciência das plantas daninhas. B. Inf. SBCPD, v. 10, p. 32, 2004.

FRIESSLEBEN, U.; POHLAN, J.; FRANKI, G. The response of Coffea arabica L. to weed competition. Café, Cacao Thecn., v. 35, n. 1, p. 15-20, 1991.
LOMBARDI NETO, F.; DRUGOWICH, M. I. Manual técnico de manejo e conservação de solo e água. Campinas: CATI, 1994. v. 2. $168 \mathrm{p}$.

MEROTTO JR, A.; VIDAL, R. A.; FLECK, N. G. Variação da competição interespecífica em milho em função do controle de plantas daninhas em faixas. Planta Daninha, v. 19, n. 2, p. 287-294, 2001.

NJOROGE, J. M. Weeds and weed control in coffee. Exp. Agric., v. 30, p. 421-429, 1994.

RONCHI, C. P. Interferferência e controle de plantas daninhas na cultura de café (Coffea arabica L.). 2002. 115 f. Dissertação (Mestrado em Fitotecnia) - Universidade Federal de Viçosa, Viçosa, 2002.

SILVA, A. A.; RONCHI, C. P. Manejo e controle de plantas daninhas em café. In: VARGAS, L.; ROMAN, E. S. (Eds.). Manual de manejo e controle de plantas daninhas. Bento Gonçalves: Embrapa Uva e Vinho, 2004. p. 337-396.

SOUZA, L. S.; VELINI, E. D.; MAIMONI-RODELLA, R. C. S. Efeito alelopático de plantas daninhas e concentrações de capim-braquiária (Brachiaria decumbens) no desenvolvimento inicial de eucalipto (Eucalyptus grandis). Planta Daninha, v. 21, n. 3, p. 343-354, 2003.

TOLEDO, R. E. B. et al. Efeitos de faixa de controle da Brachiaria decumbens no desenvolvimento inicial de plantas de eucalipto. Planta Daninha, v. 18, n. 3, p. 383-393, 2000. 